\title{
Enegrecer a Universidade para vivenciar o conhecimento
}

\section{Black out the University to experience the knowledge}

LUÍS THIAGO FREIRE DANTAS (iDa

\section{Resumo}

Este ensaio propõe um questionamento sobre a construção do ambiente universitário da filosofia e sua dificuldade em dialogar com epistemologias fora do cânone. Para isso, problematizamos a imagem de quem produz conhecimento que exclui outras alternativas epistêmicas. O interesse, assim, é propor como os corpos negros atribuem à Universidade uma retomada epistêmica que se contrapõe à colonialidade universitária fundamentada no epistemicídio.

Palavras-chave: Cânone. Colonialidade. Corpos negros. Epistemicídio. Universidade.

\begin{abstract}
This essay proposes a question about the construction of the university environment of philosophy and its difficulty in dialoguing with epistemologies outside the canon. For this, we problematize the image of those who produce knowledge that excludes other epistemic alternatives. The interest, therefore, is to propose how black bodies attribute to the University an epistemic resumption that is opposed to university coloniality based on epistemicide.
\end{abstract}

Keywords: Canon. Coloniality. Black bodies. Epistemicide. University.

\footnotetext{
a Universidade Estadual do Rio de Janeiro (UERJ), Rio de Janeiro, RJ, Brasil. Doutor em Filosofia, e-mail: fdthiago@gmail.com
} 


\section{Introdução}

Em janeiro de 2017, uma matéria divulgada pelo jornal Daily Mail do Reino Unido provocou certa polêmica tanto no ambiente universitário quanto no extrauniversitário por causa da manchete sobre os estudantes da Escola de Estudos Orientais e Africanos (SOAS) da Universidade de Londres: "They Kant be Serious! [Isso não pode ser verdade!] Estudantes Politicamente Corretos querem que os filósofos brancos, incluindo Platão e Descartes, saiam dos currículos da universidade" (PRETE, 2017)ํ․ Tal manchete explicita não somente uma má interpretação do jornal perante os interesses estudantis, mas também visibiliza uma atuação do colonialismo que é a centralidade do embate da exigência da SOAS: "quando [os estudantes] estudarem filosofia 'a maioria dos filósofos em seus cursos' devem ser orientais ou africanos". Uma exigência não descolada da realidade, se notarmos que o foco de tal Escola é o território asiático e africano, então a grade curricular deveria contemplar em grande maioria tais regiões e a filosofia ali produzida. A concretização dessa exigência revela dificuldades justamente que para inserir filósofos orientais e africanos na grade curricular filosófica universitária requer um movimento de decolonização ${ }^{2}$ para assim necessita um desmanche das expectativas coloniais da sociedade sobre a filosofia e seus representantes.

O sensacionalismo da matéria despertou inúmeros comentários até mesmo aqui no Brasil ${ }^{3}$, menosprezando as exigências desses estudantes (um diálogo mais próximo com as próprias vivências) que se trata de enfatizar a problematização das teorias dos filósofos europeus conforme o contexto colonial em que elas foram produzidas: "Se for preciso estudar os filósofos brancos, então que se ensine a partir do ponto de vista crítico. Por exemplo, dando conta do contexto colonial em que os chamados filósofos do Iluminismo escreveram" (PRETE, 2017). Reverberou até mesmo o comentário do filósofo Roger Scruton sobre os interesses dos estudantes,

\footnotetext{
${ }^{1}$ No original lemos: "They Kant be serious! PC students demand white philosophers including Plato and Descartes be dropped from university syllabus".

${ }^{2}$ A escrita decolonial ao invés de descolonial acompanha o Giro Decolonial nos inícios da década de 2000 para marcar um movimento que propõe alternativas frente à colonialidade.

${ }^{3}$ A matéria foi traduzida e publicada no tabloide Gazeta do Povo, localizado em Curitiba-PR.
} 
desafiando-os: "Se eles acham que há um contexto colonial do qual a Crítica da Razão Pura de Kant surgiu, eu gostaria de ouvi-lo” (PRETE, 2017) ${ }^{4}$.

Motivado por tal cenário de opiniões, este ensaio propõe um questionamento sobre a construção do ambiente universitário da filosofia e sua dificuldade em dialogar com epistemologias fora do cânone. Tal proposta guia-se por uma série de perguntas que procuram levar em conta a vivência da maioria discente brasileira, pois em um país localizado na América Latina com a maior parte da população sendo negra, como estamos lidando com a invisibilidade de epistemologias africanas ou latinoamericanas? A inserção destas necessariamente excluiria as europeias? Qual é o receio de evidenciar os limites de um filósofo europeu acerca de um assunto em que filósofas e filósofos africanos, asiáticos ou latino-americanos apresentam maior profundidade analítica?

Estas perguntas serão motes das seções que compõem esse ensaio. Primeiro, aludimos ao aspecto de "afastamento do mundo" como prerrogativa para legitimar conhecimentos que se diferenciam dos saberes influenciados pelo cotidiano particular de cada grupo de pessoas. Dessa forma, cria-se uma busca pelo ponto zero, um ponto em que o pesquisador ou a pesquisadora observa o mundo, mas não pode por ele ser observado/a. Em seguida, atribuímos essa prerrogativa como elemento provocador de um epistemicídio que atua silenciando corpos negros.

A pretensão é questionarmos como a ideia de filosofia está alicerçada em uma imagem que acaba excluindo outras alternativas epistêmicas. Não somente isso, mas faz com que nós esqueçamos nossa situação em uma sociedade colonizada, reproduzindo o colonialismo que normatiza a própria compreensão de ser humano e estratifica grupos populacionais.

\section{A colonialidade universitária}

Edgardo Lander (2000, p. 43) analisa como a existência de um entendimento sobre uma racionalidade atuante nas universidades latino-americanas produz uma barreira epistêmica:

\footnotetext{
4 No original lemos: "If they think there is a colonial context from which Kant's Critique of Pure Reason arose, I would like to hear it".
} 
A formação profissional [oferecida pela Universidade], a pesquisa, os textos de circulação, as revistas que são recebidas, os lugares onde são realizados os cursos de pós-graduação, os sistemas de avaliação e reconhecimento dos seus docentes, todos apontam para a reprodução sistemática de uma visão de mundo de perspectivas hegemônicas do Norte.

Tal reprodução invariavelmente beneficia a imagem "branca" ${ }^{5}$ das ciências e da própria filosofia, impossibilitando uma percepção de como estabelecemos uma rede de conhecimento que, obviamente, privilegia o funcionamento de certa ordem epistêmica. Atento a tal funcionamento, Santiago Castro-Gomez (2007) interpreta as reproduções hegemônicas do Norte global como uma manutenção da colonialidade no interior universitário - colonialidade como sendo um processo de alargamento do colonialismo através de uma avaliação étnico-racial que regula e normatiza a existência, a organização social e produção filosófica e científica das pós-colônias ${ }^{6}$. Com isso, a tendência é enfatizar a "observação colonial sobre o mundo" (CASTROGOMEZ, 2007, p. 79), justamente por essa observação formar “o ponto zero" uma ordem epistêmica de neutralidade e afastamento do mundo.

Ainda sobre essa observação, Castro-Gomez analisa que há uma fundamentação de narrativas que influem na legitimação do saber e na institucionalização da moralidade universitária. Tais narrativas têm consigo a perspectiva de formação humana que perpassa pelo progresso tecnocientífico, no qual grupos humanos precisam se adequar para se distanciar da primitividade. A Universidade, desse modo, é institucionalizada como epígono que impulsiona o progresso: "O progresso da nação depende em grande medida, que a Universidade comece a gerar uma série de sujeitos que incorporam o uso de conhecimentos úteis" (CASTRO-GOMEZ, 2007, p. 80). A outra narrativa se alinha à anterior pela via de "educação" moral da sociedade: "a Universidade busca formar os líderes espirituais da nação. A Universidade age como a alma máter da sociedade, porque sua missão é favorecer a realização empírica da realidade” (CASTRO-GOMEZ, 2007, p. 81). O problema é que na dificuldade dessa "realização empírica da realidade" há

\footnotetext{
${ }^{5}$ Aqui o termo "branca" trata-se de uma experiência de mundo que parte de uma exclusividade epistêmica de um grupo humano que se entende como universal e regula quaisquer particularidades.

${ }^{6}$ O termo "pós-colônia" tomo aqui de Achille Mbembe (2020), para quem a pós-colônia é um resultado do neoliberalismo imiscuído ao colonialismo que produz uma série absurda de violência e uma simbiose entre dominantes e dominados.
} 
estreitamento às normas socioeconômicas orientando-se para uma formação de profissionais técnicos e, por conseguinte, essa moralidade passa a se adequar ao mercado e à acumulação do conhecimento.

Consubstanciada por tais narrativas, a organização universitária caracteriza-se então pela estrutura arbórea que hierarquiza os conhecimentos, pela delimitação de uma diferença entre os diversos campos de saber, pelo estabelecimento de fronteiras epistêmicas intransponíveis e, obviamente, pelo uso de cânones para definir os procedimentos metodológicos (CASTRO-GOMEZ, 2007). Com isso, o crivo de legitimidade de uma produção de conhecimento perpassa o reconhecimento universitário por funcionar como aquilo "que estabelece fronteiras entre o conhecimento útil e o vaidoso, entre doxa e episteme, entre conhecimento legítimo e conhecimento ilegítimo" (CASTRO-GOMEZ, 2007, p. 81).

Assim, Castro-Gomez caracteriza a Universidade como referência colonial do conhecimento inscrevendo-a na "estrutura triangular da colonialidade": ser, saber e poder. Isso se fundamenta, na interpretação do autor, através do modelo epistêmico moderno/colonial da "bybris do ponto zero". O autor identifica a origem dessa bybris entre o período de 1492-1700 - antes o ser humano ocidental, a natureza e o conhecimento estariam inter-relacionados - mas com a expansão do entendimento moderno de controle racional do mundo uma busca de resultados mais eficazes tornou-se prioritária e a natureza deveria ser minuciosamente conhecida. "Isso diz que o conhecimento já não tem como fim último a compreensão das 'conexões ocultas' entre todas as coisas, mas a decomposição da realidade em fragmentos com o fim de dominá-la” (CASTRO-GOMEZ, 2007, p. 82), prevalecendo uma concepção de mundo-máquina:

Não só a natureza física, mas também o homem [, a mulher], as plantas, os animais, são vistos como meros autômatos regidos por uma lógica maquínica. Um homem doente simplesmente equivale a um relógio quebrado, e o grito de um animal ferido significa não mais do que o ranger de uma roda sem óleo (CASTRO-GOMEZ, 2007, p. 83).

Partindo desse cenário Castro-Gomez afirma que o modelo epistemológico característico da ciência moderna tem no "ponto zero" uma distância do mundo para observá-lo, porém a ciência não pode ser observada. A questão é que se manifesta a impossibilidade de alcançar esse ponto e, portanto, provoca-se uma desmesura, uma 
"bybris". Por isso, a "bybris do ponto zero" é definida como a tentativa científica de neutralidade perante os fatos do mundo que, no desejo de se tornar neutra, invalida qualquer outro conhecimento "próximo ao mundo" e, por causa disso, depara-se com sua própria impossibilidade. É a partir desse ponto que para o autor “a Universidade moderna encarna perfeitamente a 'hybris do ponto zero', e este modelo epistêmico se reflete não só na estrutura disciplinar de suas epistemes, mas também na estrutura departamental de seus programas" (CASTRO-GOMEZ, 2007, p. 83). Pela divisão em disciplinas (Sociologia, Antropologia, Física, Matemática, Filosofia) materializa-se a ideia de que a realidade deva ser fragmentada para que se alcance a certeza do conhecimento: "o que faz uma disciplina é, basicamente, recortar um âmbito do conhecimento e traçar linhas fronteiriças a respeito de outros âmbitos do conhecimento" (CASTRO-GOMEZ, 2007, p. 83). Linhas fronteiriças determinada pela estratégia de inventar as "origens" de uma disciplina:

As disciplinas constroem suas próprias origens e encenam o nascimento de seus pais fundadores. Em uma palavra, as disciplinas constroem suas próprias mitologias: Marx, Weber e Durkheim como pais da sociologia; 'os gregos' como pais da filosofia; Newton como pai da física moderna, etc. (CASTRO-GOMEZ, 2007, p. 84).

Com essa estratégia aplica-se um recorte epistêmico por solidificar os cânones necessários para a pesquisa, os temas mais pertinentes e o que deve ser conhecido pelo/a estudante que opta pela disciplina: "os cânones são dispositivos de poder que servem para 'fixar' os conhecimentos em certos lugares, fazendo-os facilmente identificáveis e manipuláveis” (CASTRO-GOMEZ, 2007, p. 84). Outra estratégia é "arborização" da estrutura universitária, na qual há uma decomposição entre faculdades, departamentos e programas. As faculdades são um tipo de refúgio das epistemes diante da qual há uma administração e controle para gerenciar certa disciplina; os departamentos pertencem aos especialistas vinculados a uma faculdade; os programas são as práticas metodológicas que confirmam a manutenção do que deve ser produzido pelos departamentos e faculdades. Por efeito, como analisa Castro-Gomez (2007, p. 84): "raras as vezes os professores podem mover-se entre um departamento e outro, muito menos entre uma faculdade e outra, porque são como prisioneiros de uma estrutura universitária, essencialmente fraturada". Além disso, cada vez mais se exige uma habilidade de gerência tal como uma 
performatividade que administra os efeitos de poder, subordinando as instituições de educação superior aos poderes globais, através do argumento de "produzir conhecimentos pertinentes" (CASTRO-GOMEZ, 2007, p. 86).

Contra essa gerência do conhecimento, a sul-africana Ivy Goduka (2000, p. 65), "uma estudiosa indígena, uma curandeira (izangoma), uma visionária (imboni), uma filósofa (ikncuba buchopho), uma sonhadora (umphuphi) e uma mulher Xhosa bem versada em formas indígenas de conhecer”, expõe uma crítica ao sistema de educação superior na África do Sul pós-apartheid por deslegitimar os conhecimentos locais a favor de uma educação global. Essa crítica ressoa como similar em outros locais no mundo, como no Brasil, pois cada vez mais a construção de um conhecimento se alinha aos ditames globais e à possibilidade de ser reconhecido pelo exterior ao invés de um diálogo com as produções de conhecimento próximas às vivências locais de cada Universidade. Em certo sentido, a decolonização perpassa o que Goduka propõe como "sintonizar e desenhar filosofias indígenas e sabedorias espirituais" em diálogo com as epistemes europeias/ocidentais.

Essa sintonia compreende variadas alternativas de perceber uma questão, muitas vezes necessitando recorrer a elementos locais para uma interpretação e modificação da realidade. Porém, isso requer uma consideração da própria estrutura universitária da filosofia para outras linguagens e ciências não comumente vistas nos currículos enquanto referências teóricas. Como alerta Goduka, houve um impedimento de anunciar, pensar, discursar na língua IsiXhosa "porque é uma linguagem não científica e bárbara que não tem lugar na academia” (GODUKA, 2000, p. 66) para reproduzir em sua mente o paradigma newtoniano-cartesiano.

Com isso, para a mente colonial, trazer ao ambiente universitário os valores locais de caráter espiritual seria trazer uma cultura morta para dentro dos recintos culturais que progridem o ser humano. Como lemos na seguinte denúncia da autora:

Adorar o Grande Espírito, uQamata, foi ridicularizado como sendo paganista. Da mesma forma, a espiritualidade indígena, a magia, a mitologia e as lendas (iintsomi) que formam a fundação dos ensinamentos indígenas e servem para preservar os rudimentos das práticas culturais e valores espirituais de um povo foram ignorados, desvalorizados e banalizados como superstição inútil, porque não estão de acordo com as formas cartesianas de racionalidade. Mentiram-me sobre meus Anciãos, ookhokho, e meus antepassados abaThembu, ooQhudeni, ooMvelase, ooNgoza kaMkhubukeli, que eles são espíritos malignos (GODUKA, 2000, p. 66). 
Percebemos nesse primeiro momento que a colonialidade desenvolve formas para manter certa hegemonia epistêmica por meio do ato de invalidar a presença de outras mais próximas dos conflitos das pós-colônias. Assim, a crítica de Goduka segue a linha de como conhecimentos conectados ao mundo são identificados pela "ciência global" como repletos de superstições sem uma racionalidade capaz de direcionar os conflitos humanos para uma realidade interligada ao todo. Caso houvesse uma atenção a outras epistemes, seria evitada a reprodução daquilo que Castro-Gomez definiu como uma “bybris do ponto zero", pois a suposta neutralidade sustenta uma hegemonia de posição-de-mundo e impossibilita a exposição dos conhecimentos subalternizados. Tanto essa sustentação de posição-de-mundo quanto a impossibilidade de afirmar outros conhecimentos se solidificam através de um movimento, o silenciamento de corpos.

\section{Corpos que falam}

O movimento de silenciamento não se direciona para os corpos brancos que precisamente são aqueles que projetam a imagem para a mente colonial de quem produz conhecimento (universal, neutro, objetivo e imparcial). Tai corpos são lidos como seres humanos capazes de identificar problemáticas sem abalar o cânone, e caso aconteça tão logo é interpretado como uma releitura. Já corpos não-brancos precisam ser humanizados e quanto mais distantes do branco, menos provável em produzir conhecimento. Essa caracterização dos corpos é bem exposta por Grada Kilomba (2019). A autora expõe como essa humanização é um processo do racismo que interioriza nas mentes coloniais e colonizadas o significado de corpos negros como "fora do lugar":

Dentro do racismo, corpos negros são construídos como corpos impróprios, como corpos fora do lugar e, portanto, como corpos que não pertencem. Corpos brancos, ao contrário, são construídos como próprios; eles são corpos 'do lugar', 'em casa', corpos que sempre pertencem. Eles pertencem a qualquer lugar: Europa; África; Norte; Sul; Oriente; Ocidente; tal como centro quanto como periferia. Através de tais comentários, acadêmicos negros são persistentemente convidados a retornar a 'seu lugar', o 'lado de fora' da academia, nas margens, onde os seus corpos são vistos como 'apropriados' e em 'casa' (KILOMBA, 2019, p. 30-31). 
O crucial dessa estratificação é que não se restringe a um caráter físico, mas também epistêmico, pois o silenciamento reverbera o controle colonial para desestruturar os corpos negros e, por consequência, transforma a Universidade em territórios de morte epistêmica. Como percebemos, aqui se desenvolve o epistemicídio, o qual para Sueli Carneiro (2005) serve ao "vitalismo da branquitude" como ferramenta de manutenção desse vitalismo como preponderante, não importando as mudanças sociais. A necessidade desse "vitalismo" de permanecer o mesmo é visível durante a reação dos grupos hegemônicos diante das ações afirmativas para o ingresso de estudantes negros no ensino superior por meio de reserva de vagas, uma reação justificada pelo receio de que tal situação promoveria a queda na qualidade do ensino superior. Em síntese, o "vitalismo da branquitude" argumenta que tais corpos produziriam pesquisas divergentes do cânone e factualmente a qualidade na produção de conhecimento perderia força. Uma desconfiança que reforça o epistemicídio: "um elo que não mais se destina ao corpo individual e coletivo, mas ao controle de mentes e corações" (CARNEIRO, 2005, p. 97).

Exercendo esse controle que aparenta uma corrida para uma linha chegada que sempre se afasta quando um corpo negro se aproxima, tal como a situação de Lélia Gonzalez, que encontrou uma série de impedimentos no departamento de Ciências Sociais da Pontifícia Universidade Católica (PUC) do Rio de Janeiro para ser chefa do departamento. Mesmo com anos de trabalho na instituição conquistou o cargo somente em maio de 1994 (meses antes do seu falecimento). Tais dificuldades, conforme interpretação de Luiza Bairros (2000), não se limitaram às posições políticas de Lélia, mas representaram a desconfiança de intelectuais brancos acerca de pessoas negras em espaços de poder, principalmente pela subjetividade de tais pessoas invariavelmente aliarem seu engajamento político à produção acadêmica:

Assumindo perspectivas que entendem ser mais coerentes com a experiência de seu povo, os negros intelectuais geralmente são vistos com desconfiança por buscar desconstruir os cânones do pensamento acadêmico que reforçam mais do que desafiam o racismo insidioso [...]. Para além dos embates no interior da academia, os negros intelectuais defrontam-se com o intermitente questionamento da militância negra que tende a opor o fazer teórico ao prático. Isto ocorreu, e ainda ocorre, embora em menor grau, por pelo menos duas razões. Em primeiro lugar porque nem sempre se percebeu 0 potencial da universidade como espaço para a atuação dos negros. Em segundo lugar, 
pela falta de entendimento quanto ao fato, para que Gramsci já alertara, de que todo grupo social produz seus próprios intelectuais. Estes, em contrapartida, ajudam a construir a identidade do grupo e aprofundam a consciência deste em relação ao papel que tem a cumprir nos planos econômico, social, político e cultural (BAIRROS, 2000, p. 19).

Aprofundando isso, retomamos Kilomba que expõe como no âmbito universitário a apresentação de pesquisas protagonizadas por pessoas negras geralmente sofre interpelações do tipo: "você tem uma perspectiva muito subjetiva"; "muito pessoal"; "muito emocional"; "muito específica"; "onde estão os fatos objetivos?” (KILOMBA, 2019, p. 51). Essa série de frases configuram-se em uma atuação do epistemicídio na estrutura do ambiente universitário edificada em “[...] um espaço onde nós somos silenciadas e onde acadêmicas/os brancas/os desenvolveram discursos teóricos que formalmente constroem-nos como a/o 'Outra/o' inferior, colocando os africanos em subordinação absoluta aos sujeitos brancos" (KILOMBA, 2019, p. 50, grifos da autora).

Tal subordinação manifesta-se simbolicamente pela boca, pois sendo o local de fala e enunciação o "vitalismo da branquitude" apropria-se e torna o corpo negro como objeto incapaz de falar por si mesmo. Essa incapacidade requer uma representação, alguém que fale por ele, ou ainda uma máscara colonial que "simboliza políticas sádicas de conquista e dominação e seus regimes brutais de silenciamento da/os chamadas/os 'Outras/os': Quem pode falar? O que acontece quando falamos? E sobre o que podemos falar?” (KILOMBA, 2019, p. 33).

Para Kilomba, a máscara é o colonialismo como um todo, pois a qualquer momento lembra ao corpo negro sua adequação às fantasias brancas alimentadas pelo próprio imaginário do corpo branco. Criando uma neurose em que a "Outra/o" é aquilo que se adequa às projeções de um "Eu”" ensimesmado. A consequência para o corpo negro é a experiência do trauma que o acompanha intermitente, por ser um resultado do contato com "a violenta barbaridade do mundo branco, ou seja, a irracionalidade do racismo que nos coloca sempre como a 'Outra/o', como diferente, como incompatível, como conflitante, como estranha/o e incomum" (KILOMBA, 2019, p. 40).

Utilizando a simbologia da máscara, Kilomba interroga acerca dos impedimentos com que corpos negros se deparam ao "falar", como se o "vitalismo 
branco" defenestrasse os segredos inventados por si mesmo. Segredos que precisariam ser negados, reprimidos, selados indefinidamente, tais como o colonialismo, o racismo e a escravidão. Uma tríade-base da modernidade em que filósofos canônicos se beneficiaram ou transformaram em sintomas sociais que não mereceriam uma atenção maior em suas investigações, porém é aplicada aos outros povos pela justificativa de "propiciar" o progresso. Contudo, essa tríade se torna um fantasma para o ser branco: "Uma vez confrontado com verdades desconfortáveis dessa bistória muito suja, o sujeito branco comumente argumenta 'não saber...', 'não entender...', ‘não se lembrar', ‘não acreditar' ou 'não estar convencido...”" (KILOMBA, 2019, p. 42, grifos da autora).

Com esse cenário, então como sair dessa armadilha criada pelo "vitalismo da branquitude"? Se para a mente colonial a equação "negro" = objeto é um fato científico, ainda é possível uma decolonização universitária? bell hooks (1989, p. 42 apud. Kilomba, 2019, p. 28) afirma que sujeitos são aqueles que "tem o direito de definir suas próprias realidades, estabelecer suas próprias identidades, nomear as suas histórias", sendo assim, a vivência de uma subjetividade negra apenas é factível quando ela descreve a própria história e não se reduz a ser descrita. Se conforme Aimé Césaire (2011, p. 269) a liberdade de um povo colonizado é possível quando há uma "retomada da iniciativa histórica", então quando a decolonização alimenta uma sensação de luta de reverberações de justificativas e argumentos coloniais é por ainda permanecer atrelada a um dispositivo da colonização? Caso a resposta seja positiva, então urge a ação da "retomada" da história de corpos negros como produtores de conhecimento.

Retomada no sentido de ao estar familiarizado com algo, ser despossuído e tomar de volta à própria vivência, já que temos em vista aqui um continente com experiências e contribuições na medicina, na arquitetura, catalogadas nas civilizações de Kemet e da Etiópia. Ainda mais com a construção de Universidades históricas como a de Al-Qarawiyyin na região atual de Marrocos, a de Timbuktu na região de Mali tornam exemplos de como o colonialismo/racismo atuou fortemente para mitigar qualquer afirmação de racionalidade ou de contribuição científica dos povos negros africanos. Por consequência, a história da humanidade foi forjada pela invisibilidade 
de grupos humanos, adentrando até mesmo nas mentes dos corpos negros uma sensação de que a Universidade é um espaço estranho e de improvável compartilhamento de vivências. Por isso, o enegrecimento universitário é uma retomada de uma vivência ancestral que foi apagada pelas patologias do "vitalismo da branquitude".

\section{Considerações finais}

Como podemos ler nesse ensaio, a reivindicação dos estudantes do SOAS não se situa em uma localidade particular, mas se conecta a uma percepção cada vez mais global de como o conhecimento orientado por uma imagem-padrão é incapaz de incluir outras epistemologias. Incapacidade proveniente de um receio de desfazer as próprias prerrogativas, ou até mesmo interrogar sobre se a produção de conhecimento está em diálogo com o mundo. Nesse sentido, a Universidade precisa deixar de ser um meio de manutenção de um cânone, retroalimentando uma visão de mundo que não atenta para a organização deste mundo além do campo visual, para absorver outras condições de escritas. Pois justamente como afirma Grada Kilomba (2019, p. 28), “escrever é um ato político":

Além disso, escrever é um ato de descolonização no qual quem escreve se opõe a posições coloniais tornando-se a/o escritora/escritor 'validada/o' e legitimada/o e, ao reinventar a si mesma/o, nomeia uma realidade que fora nomeada erroneamente ou sequer foi nomeada.

Nessa guerra de nomeação, quem sabe então, surjam as/os produtoras/es de conhecimento com seus repertórios que potencializam a vida e não expulsam o mundo das grades curriculares.

\section{Referências}

BAIRrOS, L. H. de. Lembrando Lélia Gonzalez 1935-1994. Afro-Ásia, n. 23, p. 1-21, 2000.

CARNEIRO, A. S. A construção do Outro como não-ser como fundamento do ser. Orientadora: Profa Dra Roseli Fischmann. Tese (Doutorado em Educação) — Faculdade de Educação, Universidade de São Paulo, São Paulo, 2005.

CASTRO-GOMEZ, S. Decolonizar la universidad: La hybris del punto cero y el diálogo de saberes In: CASTRO-GOMEZ, S.; GROSFOGUEL, R. (Orgs). El giro decolonial: reflexiones para una diversidad epistémica más allá del capitalismo global. Bogotá: Siglo del Hombre 
Editores; Universidad Central, Instituto de Estudios Sociales Contemporáneos y Pontificia Universidad Javeriana, Instituto Pensar, 2007.

CÉSAIRE, A. Cultura e colonização. In: SANCHES, M. R. (Org.) As malhas que os impérios tecem: textos anticoloniais, contextos pós-coloniais. Lisboa: Edições 70, 2011.

GODUKA, I. African indigenous philosophies: legitimizing spiritually centred wisdoms within the academy. In: HIGGS, Paul et al. (Org.) African Voices in Education. Landswone: Juta \& Co. Ltd, 2000.

KILOMBA, G. Memórias da Plantação: episódios de racismo cotidiano. Rio de Janeiro: Editora Cobogó, 2019.

LANDER, E. ¿Conocimiento para qué? ¿Conocimiento para quién? Reflexiones sobre la universidad y la geopolítica de los saberes hegemónicos. In: CASTRO-GOMEZ, S. (Orgs). La reestructuración de las ciencias sociales en América Latina. Bogotá: Centro Editorial Javeriano, Instituto Pensar, Pontificia Universidad Javeriana, 2000.

MBEMBE, A. Pourquoi ont-ils tous peur du postcolonial? AOC: Media, 2020. Disponível em: https://aoc.media/opinion/2020/01/20/pourquoi-ont-ils-touspeur-du-postcolonial/ Acesso em: 26 jan. 2020.

PRETE, J. They Kant be serious! PC students demand white philosophers including Plato and Descartes be dropped from university syllabus. Daily Mail, Londres, 11 jan. 2017. Disponível em: https://www.dailymail.co.uk/news/article-4098332/They-Kant-PC-students-demandwhite-philosophers-including-Plato-Descartes-dropped-universitysyllabus.html\#ixzz4qFndcjTc. Acesso em: 23 dez. 2020. 